\title{
Methyl Jasmonate: Behavioral and Molecular Implications in Neurological Disorders
}

\author{
Oritoke Modupe Aluko ${ }^{1,2,3}$, Joy Dubem Iroegbu ${ }^{2}$, Omamuyovwi Meashack ljomone ${ }^{2,4}$, Solomon Umukoro ${ }^{3}$ \\ ${ }^{1}$ Department of Physiology, ${ }^{2}$ The Neuro-Lab, School of Health and Health Technology, Federal University of Technology, Akure, ${ }^{3}$ Department \\ of Pharmacology and Therapeutics, University of Ibadan, Ibadan, ${ }^{4}$ Department of Human Anatomy, School of Health and Health Technology, \\ Federal University of Technology, Akure, Nigeria
}

\begin{abstract}
Methyl jasmonate (MJ) is a derivative of the jasmonate family which is found in most tropical regions of the world and present in many fruits and vegetables such as grapevines, tomato, rice, and sugarcane. MJ is a cyclopentanone phytohormone that plays a vital role in defense against stress and pathogens in plants. This has led to its isolation from plants for studies in animals. Many of these studies have been carried out to evaluate its therapeutic effects on behavioral and neurochemical functions. It has however been proposed to have beneficial potential over a wide range of neurological disorders. Hence, this review aims to provide an overview of the neuroprotective properties of $\mathrm{MJ}$ and its probable mechanisms of ameliorating neurological disorders. The information used for this review was sourced from research articles and scientific databases using 'methyl jasmonate', 'behavior', 'neuroprotection', 'neurodegenerative diseases', and 'mechanisms' as search words. The review highlights its influences on behavioral patterns of anxiety, aggression, depression, memory, psychotic, and stress. The molecular mechanisms such as modulation of the antioxidant defense, inflammatory biomarkers, neurotransmitter regulation, and neuronal regeneration, underlying its actions in managing neurodegenerative diseases like Alzheimer's and Parkinson's diseases are also discussed. This review, therefore, provides a detailed evaluation of methyl jasmonate as a potential neuroprotective compound with the ability to modify behavioral and molecular biomarkers underlying neurological disorders. Hence, MJ could be modeled as a guided treatment for the management of brain diseases.
\end{abstract}

KEY WORDS: Methyl jasmonate; Neuroprotection; Behavior; Neurodegenerative diseases; Depression; Anxiety.

\section{INTRODUCTION}

Jasmonates are cyclopentanone phytohormones that play an imperative role in the defense of plants against abiotic stressors and pathogenic invasions [1]. Although they were initially isolated from Jasminum grandiflorum L., a plant mostly found in tropical regions [2], they are extensively distributed in plants and some microorganisms [1]. They are cell regulators, known to activate intracellular signaling mechanisms in plant growth, defense, and response to stress triggers [3]. Their biosynthesis from

Received: July 21, 2020 / Revised: October 27, 2020

Accepted: October 28, 2020

Address for correspondence: Oritoke Modupe Aluko Department of Physiology, School of Health and Health Technology, Federal University of Technology, Akure 340252, Ondo, Nigeria

E-mail: omaluko@futa.edu.ng

ORCID: https://orcid.org/0000-0002-6385-8229 linolenic acid in plants is analogous to the synthesis of eicosanoids from arachidonic acid in animals [3,4]. The family of jasmonates includes Cis-jasmone (CJ), Jasmonic acid (JA), and Methyl jasmonate (MJ) [3]. Of all the members of the Jasmonates family, $M J$ is the most studied. $M J$ is an adaptogenic phytohormone [5] released by plant cells in response to environmental stress, injury, and pathogen invasions. It induces the synthesis of proteinase inhibitor proteins, which are involved in plants' defense against a variety of biotic and abiotic stressors [5]. On exposure of plants to stressors, $\mathrm{MJ}$ is synthesized, resulting in the activation of the proteinase inhibitor gene and subsequently, the expression of proteinase inhibitor proteins $[5,6]$. Its involvement in the adaptation of plants to stress is further supported by its increased level following plants' exposure to stressors $[5,7]$. It also plays a vital role in intracellular signaling and defense in response to pathogenic

(c) This is an Open-Access article distributed under the terms of the Creative Commons Attribution Non-Commercial License (http://creativecommons.org/licenses/by-nc/4.0) which permits unrestricted non-commercial use, distribution, and reproduction in any medium, provided the original work is properly cited. 
invasions [1]. One of the numerous adaptogenic properties of $\mathrm{MJ}$ relies on its ability to regulate the activities of antioxidants and combat the harmful effects of oxidant molecules [8].

Jasmonates and its derivatives are widely recognized in the practice of aromatherapy for depression, tension, nervousness, anxiety, and mental alertness [5,9]. Earlier experimental studies on MJ were largely on its therapeutic potentials on cancer cells that have attracted global recognition as a promising antitumor agent. The uniqueness of $\mathrm{MJ}$ in cancer pathology is related to its ability to preferentially kills cancer cells via several unrelated molecular mechanisms without causing damage to normal body cells. These findings have been described as inspiring evidence that may encourage its development for the treatment of cancer and other debilitating diseases that require prolonged therapy $[1,5,7,10-15]$. Meanwhile, the possibility of its potential usefulness in neuropsychiatric disorders stemmed from the reports of Hossain et al. [16], which have shown that MJ exhibited sedative effect and enhanced GABAergic neurotransmission. These findings have led to extensive studies on the effects of $\mathrm{MJ}$ on neurological disorders and the mechanisms underlying its neuroprotective activity in rodents [17-23]. This review presents the documented evidence on the neuroprotective activities of MJ and the mechanisms underlying its therapeutic potentials in neurological disorders. It also highlights the mechanisms by which the adaptogenic-like property of MJ could help alleviate chronic stress-induced psychopathologies.

\section{SAFETY AND TOXICITY}

The ability of $\mathrm{MJ}$ to offer cellular protection has generated more attention for its potential use as a therapeutic agent in various disorders and diseases. This has led to the screening of MJ for potential toxicity by several authors $[1,2,7,10,12,24,25]$. In an investigation by Flescher [12], and Cohen and Flescher [1], MJ administration preferentially killed cancer cells, without affecting normal body cells. Umukoro and Olugbemide [2] also reported no case of toxicity or death in mice after administering $100-$ $500 \mathrm{mg} / \mathrm{kg}$ of MJ. However, results of several studies on acute toxicity, skin irritation, mucous membrane (eye) irritation, skin sensitization, phototoxicity, and photoallergy of $M J$ indicated that the $\mathrm{LD}_{50}$ for oral administration was
$>5 \mathrm{~g} / \mathrm{kg}$, and for skin use, the $\mathrm{LD}_{50}$ was $>2 \mathrm{~g} / \mathrm{kg}$. Additionally, no irritation was observed in the human repeated-insult patch test and several animal studies. Furthermore, no irritation was detected in the mucous membrane test. Sensitization reactions in animal and human studies and photo-irritation and photoallergy studies in humans did not show any significant toxicity [25]. This finding further support previous investigations, which show that $\mathrm{MJ}$ is safe, as it is not toxic to normal body cells $[1,7]$. Likewise, the US Federal Environmental Protection Agency in 2013 issued MJ an exclusion for tolerance requirement test as it was observed to be naturally-available in human nutrition [26]. The Food and Agriculture Organization/World Health Organization also approved MJ amongst other food additives [27]. MJ was also detected to have no toxic outcome in all experiments involving all drug routes $[14,25]$.

\section{METHYL JASMONATE MODIFIES BEHAVIORS ASSOCIATED WITH NEUROLOGICAL DISORDERS}

MJ has been implicated in various behavioral modifications, such as anxiety, depression, aggression, memory among others, using experimental animal models. These are summarized in Figure 1 and Table 1.

\section{Anxiety/Anxiolytic Activity}

Anxiety is a disorder of the central nervous system (CNS) associated with an imbalance between excitatory and inhibitory impulses in the brain. These imbalance areas result in decreased GABAergic and increased glutaminergic neurochemical pathways respectively [28-32]. Anxiety manifests in various ways like fear, eating disorder, worry, suicidal tendencies in humans [22]. Several studies have explored the anti-anxiolytic potential of MJ. Most of which used mice models. Umukoro et al. [22] demonstrated the anti-anxiolytic effect of MJ on unpredictable chronic mild stress (UCMS)-induced mice while studying the explorative behavior of the mice in a light/dark transition test and elevated plus maze (EPM) test. In the EPM test, $\mathrm{MJ}$ reduced the frequency and extent of time spent in the closed arm in UCMS-induced mice. MJ also reduced the time spent by mice in the dark compartment in a light/dark transition test of UCMS-induced mice. All these observations suggest the anti-anxiogenic activity of MJ [22] 


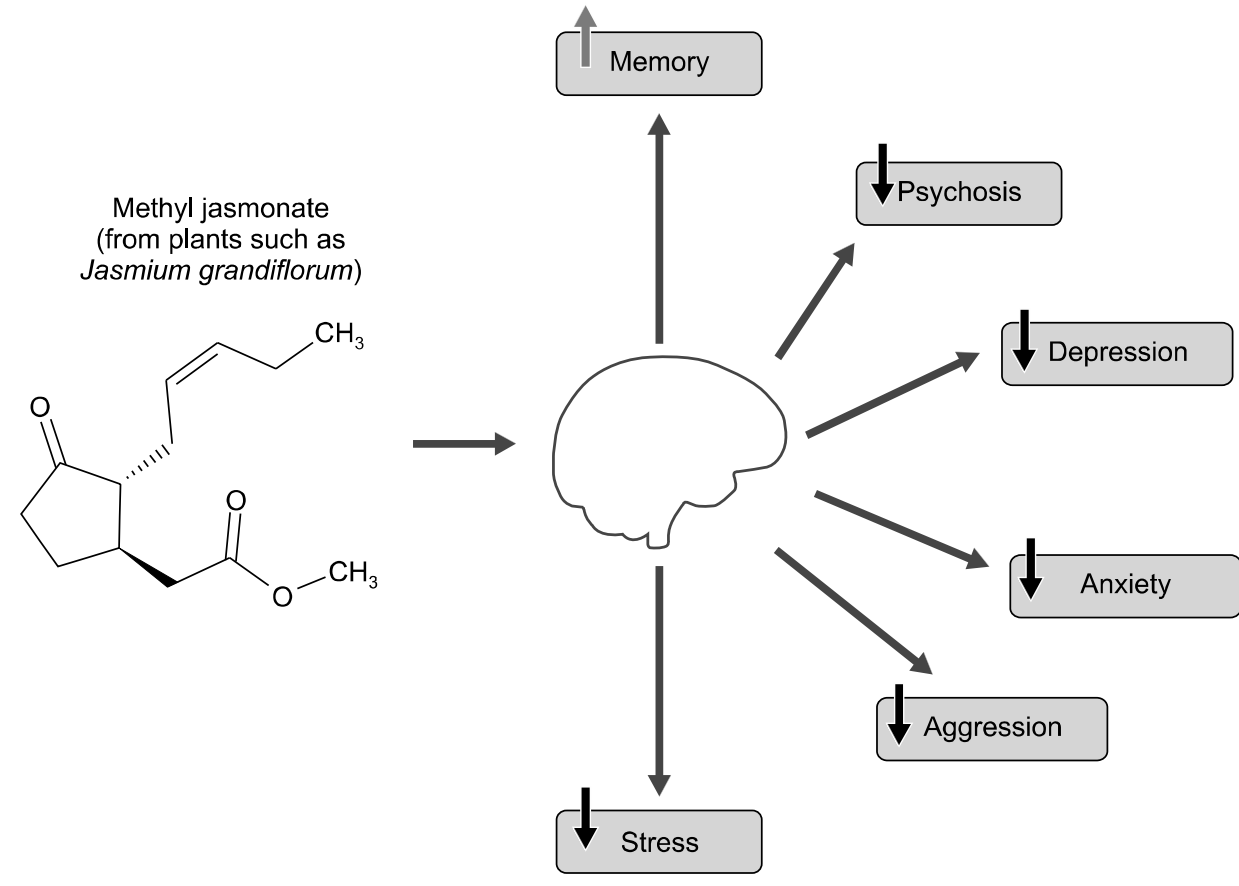

Fig. 1. MJ improves behavioral deficits associated with neurological disorders.

MJ, Methyl jasmonate.

Table 1. Summary of behavioral modifications of $\mathrm{MJ}$ in animal models

\begin{tabular}{lllc}
\hline Disorders & \multicolumn{1}{c}{ Models } & \multicolumn{1}{c}{ Effects } & References \\
\hline Anxiety & Elevated plus maze (EPM) & $\begin{array}{l}\text { Reduced frequency and duration of time spent by UCMS-induced } \\
\text { mice in the closed arm }\end{array}$ & {$[21]$} \\
& Light/dark test & Reduced time spent in the dark compartment & {$[21]$} \\
Depression & Tail suspension test & Reduced latency period in UCMS-induced mice & {$[17,36]$} \\
& Forced swim test & Reduced immobility period & {$[36]$} \\
& Sucrose preference test & Increased sucrose intake initially reduced by UCMS & {$[17]$} \\
Aggression & Isolation-evoked paradigm & Decreased aggressive behaviors & {$[41]$} \\
& Resident-intruder paradigm & Decreased aggressive behaviors & {$[41]$} \\
Memory & Passive avoidance paradigm & Increased latency period & {$[18]$} \\
& Y-maze & Increased alternation behavior & {$[19,20]$} \\
& Object recognition test & Increased discrimination index & {$[19]$} \\
Antipsychotic & Bromocriptine-induced stereotype & Reduced stereotyped behavior & {$[16]$} \\
& Ketamine-induced stereotypy & Reduced stereotyped behavior & {$[16]$} \\
Anti-stress & Forced swim endurance test & Delayed first occurrence of immobility shortened immobility & {$[22]$} \\
& & period increased active swimming time & {$[22]$} \\
& Anoxic tolerance test & Prolonged latency to the first appearance of anoxic convulsions & {$[21]$}
\end{tabular}

MJ, Methyl jasmonate; UCMS, unpredictable chronic mild stress.

\section{Depression}

Depression is a prevalent disorder that negatively impacts the quality of life worldwide. It affects about $20 \%$ of the world's population and is typically higher in females than in males with a ratio of 5:2. Preclinical and clinical investigations have implicated serotonin and norepinephrine in its pathogenesis $[33,34]$. The deficiency of these monoaminergic transmitters in the brain is reported to be one of the most significant etiological factors for the cause of depression. The recurrent nature of depression and its numerous triggers have made it difficult to manage [34-36]. These have led to increased interest in researching more effective antidepressants $[37,38]$. In a study conducted by Adebesin et al. [18], and acute stress model of 
tail suspension test (TST) was adapted to investigate the antidepressant-like property of MJ in UCMS-induced mice. An increased latency period was observed in UCMS-induced mice. This period was significantly reduced, following treatment with MJ, indicating antidepressant-like property [18]. This finding is consistent with that of Umukoro et al. [37] where acute stress models of TST and forced swim test (FST) were adapted in mice to study the antidepressant activity of MJ. MJ significantly decreased the period of immobility in both tests. Adebesin et al. [18] went further by using the sucrose preference test to evaluate the anti-depressant activity of MJ. This test is used to evaluate anhedonia (inability to experience pleasure), a key symptom of depression in humans. They reported that $\mathrm{MJ}$ attenuated impaired sucrose intake in rodents initially exposed to UCMS [18]. Biochemical evaluations have also been carried out to confirm the anti-depressant property of MJ. In a study by Zomkowski et al. [39], MJ reduced serotonin levels [39]. Studies have shown also that the anti-immobility exhibited by antidepressants in the FST and TST is mediated through the facilitation of both serotonergic and noradrenergic neurotransmissions [37]. Additionally, Umukoro et al. [37] employed the yohimbine lethality test to elucidate the role of monoaminergic transmitters in the antidepressant-like activity of MJ. Antidepressants are known to synergistically potentiate the lethality of yohimbine. In the study, intraperitoneal injections of MJ at doses of $25 \mathrm{mg} / \mathrm{kg}$ and $50 \mathrm{mg} / \mathrm{kg}$, significantly increased the lethal effect of yohimbine. Yohimbine is an $\alpha_{2}$-adrenergic receptors antagonist that stimulates sympathetic centers in the brain, resulting in increased sympathetic discharge in the CNS and peripheral nervous system (PNS) [37]. Antagonism of $\alpha_{2}$-adrenergic receptors promotes the release of noradrenaline due to increased central sympathetic activity and induces serotonin release, further contributing to the overall toxicity caused by yohimbine. MJ synergistically potentiate the lethality of yohimbine by allowing more amines to get to receptors in high quantities, either by impeding their reuptake or by decreasing their inactivation, thus suggesting the involvement of monoaminergic transmitters in its antidepressant property in mice [37].

\section{Aggression}

Aggression is a deliberate series of actions that inflict harm on another organism and is a major component of the stress-syndrome. It is characterized by low tolerance to frustration and studies have shown that feeling of frustration results from prolonged stress $[40,41]$. Aggression may manifest itself as a defensive or offensive behavior. Although aggression and depression are diagnostically categorized differently by the psychiatric classification systems Diagnostic and Statistical Manual of Mental Disorders 4th edition, they are however clinically and biochemically related $[35,37]$. The serotonergic system is implicated in both disorders [35]. This is proven by alleviated symptoms of depression and aggression when serotonin receptor agonists and uptake inhibitors were administered [35]. In a study by Umukoro et al. [42], MJ (1, $5,10 \mathrm{mg} / \mathrm{kg}$, intraperitoneally [i.p.]) had a dose-dependent decrease in aggressive behaviors in resident-intruder and isolation-evoked paradigms (both measures offensive aggression) in mice. Although MJ has an anti-aggressive activity, it, however, does not impair the defense mechanism of the animals. These findings suggest the therapeutic usefulness of $\mathrm{MJ}$ as an anti-aggressive agent. Its ability to maintain the defense mechanism in animals suggests that it could be a better therapeutic approach to aggressive behaviors than antipsychotics and high doses of benzodiazepines which tends to impair the defensive mechanisms of organisms [43]. Of all the neurochemicals associated with aggressive behaviors, reduced 5-HT has been recurrently linked with aggression by numerous authors $[43,44]$. This hypothesis was further proven using a 5- $\mathrm{HT}_{1}$ knockout rodents [40-46] (Table 1).

\section{Memory/Cognitive Enhancement}

$\mathrm{MJ}$ is used extensively in aromatherapy as a therapeutic agent for memory dysfunction [9]. In a study conducted by Umukoro et al. [22], intraperitoneal injection of $\mathrm{MJ}$ $(25,50$, and $100 \mathrm{mg} / \mathrm{kg})$ improved memory performance in mice exposed to UCMS. MJ was further shown to reverse UCMS-induced neurodegeneration in the sub-granular zone of the dentate gyrus and the pyramidal layer of the CA3 [22]. These learning and memory associated regions of the brain have been reported to exhibit loss of dendritic spines [47] and a reduced number of synapses [48] following UCMS. The results of the study established that UCMS produced the death of neuronal cells in the pyramidal layer of the CA3 and the sub-granular zone of the dentate gyrus of the hippocampus, the regions of the brain that plays vital roles in learning and memory [22]. 
Thus, a decrease in hippocampal density may lead to loss of memory function [49]. Previous clinical studies have linked reduced hippocampal volume to memory and cognitive impairment in patients with Alzheimer's disease (AD) $[49,50]$. Thus, oxidative stress-mediated hippocampal neuronal degeneration highlights memory impairment due to chronic stress. However, there are suggestions that compounds with a neuroprotective property may be of benefits in chronic stress-induced cognitive deficits and other neuropsychiatric disorders [51,52]. In another study, Eduviere et al. [19] used the passive avoidance paradigm to evaluate the influence of $\mathrm{MJ}$ on rat memory. This model uses aversive stimuli associated with fear as a condition for learning and memory acquisition $[53,54]$. This model assesses both the role of the hippocampus in memory [55] and the amygdala in fear-conditioned learning and memory [56]. It tests the ability of rodents to suppress motor activities to avoid an aversive event, which is dependent on the capability of the organisms to recall the unpleasant experiences [19]. The anti-amnesic activity of MJ was demonstrated using a passive avoidance task. $\mathrm{MJ}$ increased the latency period indicating an increase in the ability to retain and retrieve a memory. This test also demonstrated the mitigating effect of $\mathrm{MJ}$ pre-treatment on scopolamine-induced memory deficit. The test also demonstrates the attenuating effect of MJ on liposaccharide-induced amnesia. These findings further support the hypothesis that MJ has a positive effect on retention and retrieval of memory and that it plays a vital role in fear-conditioned memory. In different behavioral studies conducted by Umukoro and Eduviere [21] and Eduviere et al. [20] using the Y-maze paradigm, MJ attenuated memory deficits induced by lipopolysaccharide by increasing the alternation behavior of mice. The Y-maze is used to access spatial working memory, which is usually impaired in patients with AD. Therefore, heightened spatial working memory following MJ pretreatment indicates the anti-amnesic and memory-enhancing activity of MJ. Eduviere et al. [20] also used the object recognition test to assess the effect of $\mathrm{MJ}$ on the recognition memory of mice. The results showed that MJ significantly improved memory and attenuated scopolamine-induced memory impairment [20]. UCMS-induced memory dysfunctions were also attenuated by MJ via other mechanisms including Nrf2 expressions, antioxidant and monoaminergic systems [57].

\section{Antipsychotic}

Psychosis is a form of mental illness characterized by abnormal behaviors with little or no touch with reality [58]. It is characterized by multiple symptoms affecting thoughts, emotion, perception, and volition. It is a severe form of mental illness affecting the quality of life of the affected individuals [17]. Although pharmacological interventions have been the backbone of treatment of the disease, the use of antipsychotic drugs has certain limitations. These include the incidences of poor adherence, limited responses, and other incapacitating outcomes [59]. More notably, these drugs have failed to alter the course of the disease but are known to only provide symptomatic relief [17]. Likewise, the associated negative symptoms and memory deficits are not relieved by the antipsychotics [60-62]. Thus, the need to search for new drugs, especially agents with potential memory-enhancing effects as alternative treatments for psychotic disorders. Annafi and colleagues [17] adapted the bromocriptine-induced and ketamine-induced stereotypes as models to screen for the antipsychotic-like effect of MJ. It was reported that MJ demonstrated reduced stereotyped behaviors such as persistent sniffing, chewing, intense licking and head movements in mice, suggesting the antipsychoticlike property of MJ [17] (Table 1).

\section{Anti-stress}

Increasing the prevalence of physical, biological, or psychological stressors lead to an increase in stress and subsequently a rise in dyshomeostasis [63,64]. Organisms normally respond to acute stress by adapting to the changes in their environment. However, prolonged stress leads to illness or cell damage. Prolonged stress has been implicated in a variety of diseases such as hypertension, immune dysfunction, cancer, and several neurodegenerative disorders [23,64]. Adaptogens are a classified group of substances with the ability to improve the mental and physical performances of organisms during exposure to stressful stimuli [65]. Numerous studies have employed behavioral, and biochemical techniques to demonstrate the anti-stress property of MJ $[22,23]$. MJ decreased the immobility time in FST and increased the latency to convulsion in the hypoxia test in mice exposed to acute stress [23]. MJ was shown to reduce the level of corticosterone secretion in stressed mice indicating its adaptogenic-like property. Corticosterone induces brain damage by in- 
creasing the intracellular level of oxidative stress. Chronic stress is known to trigger corticosterone release via the hypothalamic-pituitary-adrenal axis. This finding is further backed up by an increase in the adrenal gland and liver size which was noticed in UCMS-induced rats. Increased corticosterone levels can cause further damage via oxidative stress [50,66] and neuroinflammation [67]. MJ also decreased and increased the levels of malondialdehyde (MDA) and glutathione (GSH) which were originally increased and reduced respectively in the brains of mice exposed to UCMS. MJ subsequently attenuated the increased oxidative level induced by UCMS [18,22,57]. MJ has also been shown to possess anti-fatigue property via its effect on the enzymes of the purinergic system [68].

\section{MECHANISM OF MJ MODULATORY ACTIVITIES}

\section{Antioxidant}

Oxidative stress has been implicated as a mechanism of cell damage and by extension, neuronal cell death. Oxidative stress occurs when there is a higher level of reactive oxygen species compared to antioxidants in the body. Various environmental stressors trigger the production of free radicals, which initiate a series of events leading to neurodegeneration $[69,70]$. Also, the inflammatory mediators released by injured neural cells additionally augment the production of free radicals resulting in neuronal cell death [69]. MJ amongst other adaptogens exhibits antioxidant property (Fig. 2). This was seen in studies where MJ decreased and increased the levels of MDA and GSH which were originally increased and reduced respectively in the brains of UCMS-treated mice $[20,22,57,71]$. In another study by Shanmugarajan [72],

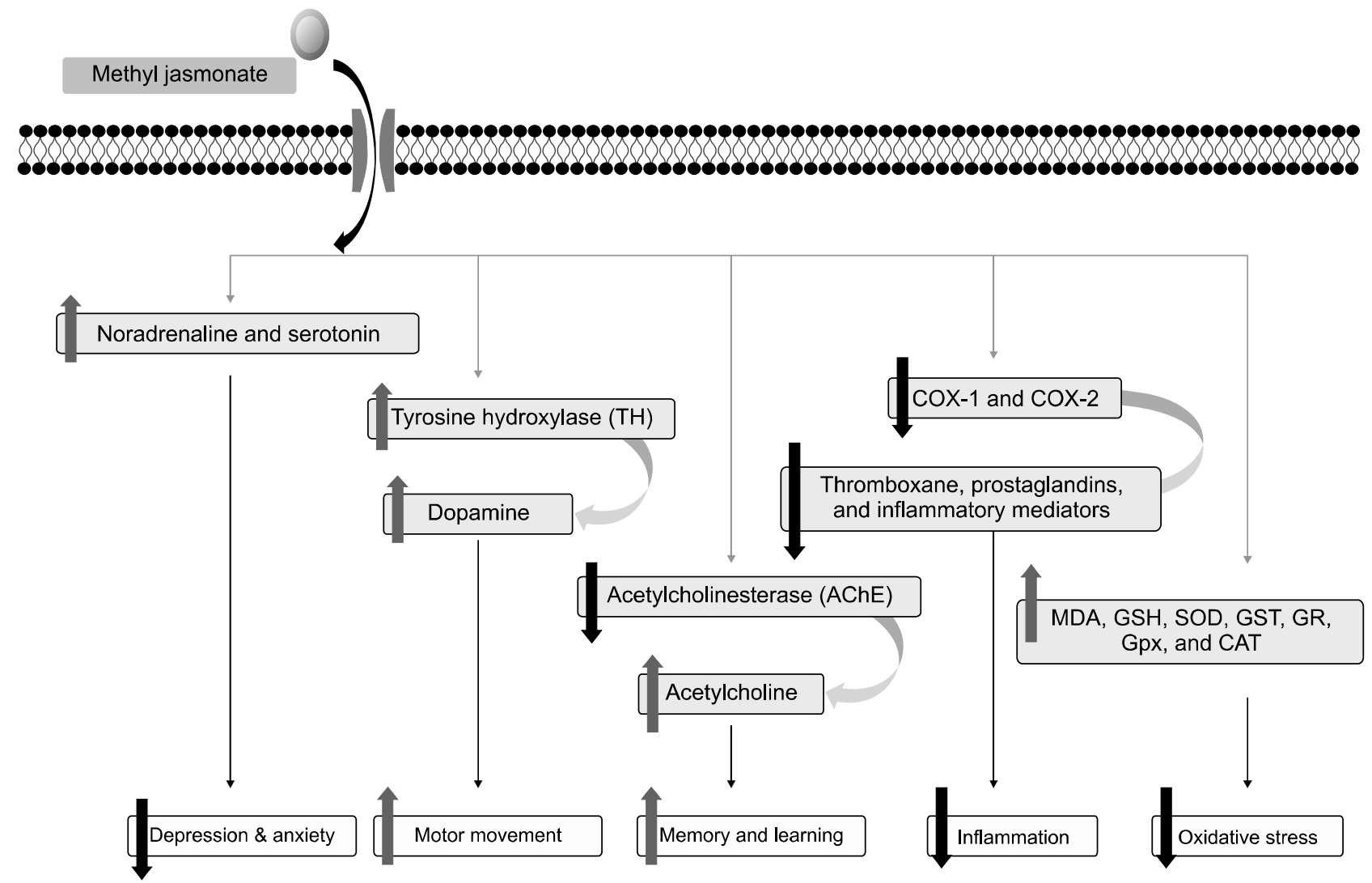

Fig. 2. Schematic diagram showing the molecular mechanisms underlying the therapeutic potential of MJ in neurological disorders. MJ, Methyl jasmonate; MDA, malondialdehyde; GSH, glutathione; SOD, superoxide dismutase; GST, glutathione-S-transferase; GR, glutathione reductase; GPx, GSH Peroxidase; CAT, catalase. 
MJ significantly increased the activity of superoxide dismutase, glutathione-S-transferase, glutathione reductase, GSH Peroxidase, and catalase compared to the lipopolysaccharide-induced group, which further confirmed its antioxidant activity.

\section{Inflammatory Biomarkers}

Injured tissues undergo inflammatory response to limit the level of damage and enhance healing [73]. Inflammation is mostly the underlying cause of pain. And also manifest in other forms such as redness, warmth, swelling, and loss of functions [74]. Anti-inflammatory drugs are designed to inhibit the action of cyclooxygenase enzymes (COX-1 and COX-2). These enzymes are responsible for the formation of prostaglandins, which are potent mediators of inflammation [75]. Chronic stress has also been linked to an increase in the release of pro-inflammatory cytokines, neuroinflammation, and subsequently depressive-like behaviors [66]. These inflammatory markers have been linked to the pathogenesis of neurodegenerative diseases such as Alzheimer's disease [76,77]. Interleukin-1 $\beta$ (IL-1 $\beta$ ) for example, is a well-known powerful pro-inflammatory cytokine with pleiotropic functional and behavioral functions $[78,79]$. IL-1 $\beta$ activates microglia and increases blood-brain barrier permeability, which promotes leukocyte permeation and upregulation of other pro-inflammatory molecules such as prostaglandin E2 (PGE2) and TNF- $\alpha[78,79]$. Clinical studies have linked elevated brain levels of inflammatory biomarkers in AD patients $[78,80]$. Also, a causative connection between IL-1 $\beta$ brain levels and memory deficits has been well reported in numerous literature $[80,81]$. Due to the structural similarity between $\mathrm{MJ}$ and anti-inflammatory prostaglandins, investigations are being carried out to ascertain its therapeutic potential for inflammatory disorders [5]. Lee et al. [82] and Dang et al. [4] investigated the anti-inflammatory potential of $\mathrm{MJ}$ in cultured cells. The inhibition of the NF- $\kappa B$ signaling pathway led to the confirmation of the anti-inflammatory potential of MJ [82]. A similar pathway was observed in plants resulting from an increased level of jasmonate secretion following infections or injuries [1]. Umukoro and Eduviere [21] further examined the effect of MJ on inflammatory biomarkers in mice brain following lipopolysaccharide injection. In that study, MJ reduced the level of PGE2, inflammatory cytokines (TNF- $\alpha$ and IL-1 $\beta$ ), COX2, iNOS, and NF- $\kappa B$. These findings further suggested the anti-neuroinflammatory activity of $\mathrm{MJ}$. MJ $(5-20 \mathrm{mg} / \mathrm{kg}$, i.p.) reduced the increased level of TNF- $\alpha$ in the brains of mice subjected to UCMS. MJ was also suggested to mitigate UCMS-induced anti-depressive behaviours via its inhibiting of oxidative stress and neuroinflammation [18]. Previous studies have also demonstrated the capability of MJ to silence genes involved in the synthesis of proinflammatory cytokines [4,83].

\section{Neurotransmitter Regulation}

Neurotransmitters are vital biochemical molecules that regulate behavioral and physiological functions in the CNS and PNS. Consequently, the study of neurotransmitters in biological samples has immense clinical and pharmaceutical importance [84]. MJ, an adaptogen, has been shown to regulate the synthesis and action of various neurotransmitters (Fig. 2). It enhances both serotonergic and noradrenergic transmissions [37]. It acts as a $5-\mathrm{HT}_{1}$ receptors agonist, thereby enhancing serotonergic neurotransmission [42]. Studies incriminating noradrenaline and serotonin in the pathogenesis of depression are detailed in both preclinical and clinical pieces of literature $[2,33,34,36,85]$. Various agents such as MJ with antidepressant activity in rodents increase the extracellular availability of amines in the brain $[37,86]$. Although the exact mechanism of action of $\mathrm{MJ}$ needs to be explored before coming to any conclusions on its mechanism of action, preliminary investigations suggest that its antidepressant-like effect may involve serotonergic and noradrenergic mechanisms [37]. Additionally, MJ significantly reduces acetylcholinesterase activity in mice brains increasing brain-level acetylcholine. Acetylcholine is an essential neurotransmitter in the process of learning and memory $[20,87,88]$. There is also evidence of modulation of the monoaminergic system vis-à-vis adrenaline, dopamine, serotonin, and monoamine oxidase by MJ [57]. MJ also increases the immunoexpression of tyrosine hydroxylase in the midbrain and striatum of rotenone-induced rats [89]. Reduced tyrosine hydroxylase expression has been implicated in dopamine depletion [90,91]. These changes suggest the regulating activity of $\mathrm{MJ}$ on neurotransmitter synthesis and activity in the CNS.

\section{Neuroregeneration}

A key obstacle for neural repair is the weak re- 
generative ability of injured neurons, although the neonatal brain has more capacity for recovery than the adult brain. There are various reports on the role of some agents in promoting the regeneration of injured and degenerating neurons in the brain [92]. In a study by Umukoro et al. [22], MJ reduced the extent of neuronal damage in the pyramidal layer of the CA3 and the sub-granular layer of the dentate gyrus of mice subjected to UCMS [22]. They also quantified the neuronal cell population and reported increase neuronal density in the pyramidal layer of the CA3 and the sub-granular layer of the dentate gyrus in UCM-stressed mice following treatment with MJ [22]. Similar results were seen in a study by Eduviere et al. [93] where $M J$ improved neuronal structure and density in the prefrontal cortex and CA1 of mice treated with lipopolysaccharide [93]. In another study, MJ reduced cytoarchitectural alterations and loss of neurons in the striatum of rotenone-treated rats [89]. MJ also significantly reversed structural alterations of the dendritic spine and improved dendritic density in rotenone-treated rats [89]. Additionally, it also reduced the loss of dopaminergic neurons in the midbrain of rotenone-rats [89].

\section{THERAPEUTIC POTENTIAL OF MJ IN NEURODEGENERATIVE DISEASES}

\section{Alzheimer's Disease}

Progressive memory loss is a major feature of Alzheimer's disease, a neurodegenerative disorder. Its prevalence increases with age [94]. Its pathohistological hallmark includes neurodegeneration of brain regions associated with learning and memory like the hippocampus [94]. It is also associated with the loss of cells involved in the cholinergic pathway. Brain cells are highly susceptible to the damaging effect of reactive oxidative species (ROS) due to their elevated rate of utilizing oxygen and reduced antioxidant defense systems [20]. ROS initiates lipid peroxidation, which triggers neuronal degeneration especially in the cholinergic system and subsequently Alzheimer's disease [20]. The role of oxidative stress in AD is confirmed by increased levels of MDA in post-mortem brains [95-97]. The potential of MJ as a therapeutic agent for the treatment of Alzheimer's disease has been explored by numerous studies. MJ attenuated memory deficits induced by lipopolysaccharide by increasing the alternation behavior of mice subjected to the Y-maze test [21].
The Y-maze is used to access spatial working memory, which is usually impaired in AD. Therefore, enhanced spatial working memory following MJ treatment indicates its anti-amnesic and memory-enhancing activity. The histomorphological study by Umukoro et al. [22] demonstrated the ameliorative effect of MJ on UCMS-induced neuronal damage in the pyramidal and sub-granular regions of CA3 and DG respectively mice [22]. Neuronal damage in the hippocampus has been frequently linked to AD. MJ also attenuates the depleting population of hippocampal neurons in UCMS-subjected mice, further proving its neuroprotective effect. Since several neurochemical studies have been linked to neuroinflammation with $\mathrm{AD}$ pathogenesis [76,77]. Umukoro and Eduviere [21] accessed the therapeutic potential of MJ for AD by examining various neuroinflammatory biomarkers in lipopolysaccharide-treated mice. Their results showed a reduction in the level of PGE2, inflammatory cytokines (TNF- $\alpha$ and IL-1 $\beta$ ), COX2, iNOS, and NF- $\kappa$ B following MJ treatment. Inhibiting factors involved in the inflammatory process could be a useful therapeutic approach for this disorder [21]. Thus, it is safe to infer that the ability of $M$ J to overturn IL-1 $\beta$, PGE2, and TNF- $\alpha$ levels suggests an important role in enhancing memory. Also, MJ suppressed the expression of $A \beta 1-42$ in the brain of mice treated with lipopolysaccharide, which suggests memory-enhancing property. An increased level of $A \beta 1-42$ induces neuronal death, characterizing the pathological hallmark of $A D$ $[98,99]$. Additionally, excessive accumulation of $A \beta$ in the brain further exacerbates oxidative stress and increases the inflammatory responses in progress, thus spreading neuroinflammation that results in progressive neurodegeneration and loss of cognitive functions in lipopolysaccaride-treated animals [77,98-100]. The attenuating effect of $M J$ on the level of $A \beta$ signifying its anti-amyloid genesis-like effect. It is also imperative to note that $M$ J is generally safe for use in humans, as it forms a major component of our diets like fruits and vegetables, thereby making it a promising therapeutic agent for AD [5].

\section{Parkinson's Disease}

Parkinson's disease (PD) is the second most popular neurodegenerative disease and is generally believed to primarily affect the dopaminergic neurons of the substantia nigra $[101,102]$. The pathological progression of PD is frequently believed to be a simple process that in- 
cludes selective degeneration of the nigrostriatal pathway and a concurrent depletion in striatal dopamine [103]. This model has directed the development of the present therapies for PD and the investigations for new ones. Most of these focus on alleviating motor symptoms rather than modifying the disease [103]. The recognition of several non-motor symptoms of PD related to the degeneration of non-dopaminergic transmitter systems [104] has made these therapies less efficient. These non-motor symptoms include olfactory dysfunction, sleep abnormalities, gastrointestinal dysfunction dysfunction, anxiety, depression, and pain [105]. This, together with the fact that medications like levodopa lose efficiency and cause dyskinesias and behavioral anomalies in many patients, calls for the development of an efficient therapy that targets both the motor and non-motor pathway. Although there are numerous studies on the ameliorative potential of MJ on various non-motor symptoms associated with $\mathrm{PD}$, it is however not certain if these signify a therapeutic effect of MJ against Parkinson's disease. MJ attenuated the anxiety-like effect of UCMS in mice [22]. This is consistent with the result seen in a study by [18] where MJ $(5-20$ $\mathrm{mg} / \mathrm{kg}$, i.p.) improved spontaneous muscle activities which were initially decreased by UCMS in mice. MJ reduced the immobility period in FST and TST [37]. The effect of MJ on motor symptoms was studied by Alabi et al. [89]. It reversed rotenone-induced deficits in locomotor activity and rearing behavior in rats. It significantly inhibited rotenone-induced dopamine reduction in the striatum, midbrain, and prefrontal cortex and increases the expression of tyrosine hydroxylase and dopamine in the striatum and the substantia nigra of rotenone-induced rats [89]. With the loss of dopaminergic neurons, the local supply of dopamine has been associated with motor deficits [106]. MJ also improves histomorphology by preventing and reverting neuronal damage in the $\mathrm{SN}$ and striatum of rotenone-induced rats. It preserved the dendritic network in the substantia nigra and striatum of rotenone-induced rats [89].

\section{CONCLUDING REMARKS}

The pathogenesis of many neurologic disorders and neurodegenerative diseases have causative associations with oxidative stress, inflammation, and neurotransmitter dyshomeostasis. These disorders exhibit symptoms such as anxiety, depression, aggression, psychosis, and memory impairment. Recent evidence highlighting the therapeutic potential of $\mathrm{MJ}$ in managing these symptoms and by extension, neurological disorders are reviewed. Reports from different studies reported $\mathrm{MJ}$ to possess the abilities to act as an antioxidant, anti-inflammatory, anti-neurogenerative, and as a neurotransmitter-regulating agent. Its neuroprotective and anti-neurodegenerative properties in the rodents' brains were also implicated in Alzheimer's and Parkinson's disease. Although various studies are highlighting the neuroprotective property of $\mathrm{MJ}$, none has examined the exact mechanism of MJ. Therefore, further understanding of the mechanism by $\mathrm{MJ}$ acts will give better insight into modeling MJ as a targeted therapy for managing the diseases of the brain.

\section{Conflicts of Interest}

No potential conflict of interest relevant to this article was reported.

\section{Author Contributions}

Concept and design: Oritoke Modupe Aluko, Omamuyovwi Meashack ljomone. Manuscript drafting: Oritoke Modupe Aluko, Joy Dubem Iroegbu. Critical revision: Omamuyovwi Meashack ljomone, Solomon Umukoro.

\section{ORCID}

Oritoke Modupe Aluko

https://orcid.org/0000-0002-6385-8229

Joy Dubem Iroegbu

https://orcid.org/0000-0002-6518-1856

Omamuyovwi Meashack ljomone

https://orcid.org/0000-0002-0933-8409

Solomon Umukoro https://orcid.org/0000-0002-4276-5875

\section{REFERENCES}

1. Cohen S, Flescher E. Methyl jasmonate: a plant stress hormone as an anti-cancer drug. Phytochemistry 2009;70: 1600-1609.

2. Umukoro S, Olugbemide AS. Antinociceptive effects of methyl jasmonate in experimental animals. J Nat Med 2011; 65:466-470.

3. Besson JCF, de Carvalho Picoli C, Matioli G, Natali MRM. Methyl jasmonate: a phytohormone with potential for the treatment of inflammatory bowel diseases. J Pharm Pharmacol 2018;70:178-190. 
4. Dang HT, Lee HJ, Yoo ES, Hong J, Bao B, Choi JS, et al. New jasmonate analogues as potential anti-inflammatory agents. Bioorg Med Chem 2008;16:10228-10235.

5. Cesari IM, Carvalho E, Figueiredo Rodrigues M, Mendonça Bdos S, Amôedo ND, Rumjanek FD. Methyl jasmonate: putative mechanisms of action on cancer cells cycle, metabolism, and apoptosis. Int J Cell Biol 2014,2014:572097.

6. Farmer EE, Ryan CA. Interplant communication: airborne methyl jasmonate induces synthesis of proteinase inhibitors in plant leaves. Proc Natl Acad Sci U S A 1990;87:77137716.

7. Rotem R, Heyfets A, Fingrut O, Blickstein D, Shaklai M, Flescher E. Jasmonates: novel anticancer agents acting directly and selectively on human cancer cell mitochondria. Cancer Res 2005;65:1984-1993.

8. Parra-Lobato MC, Fernandez-Garcia N, Olmos E, AlvarezTinaut MC, Gómez-Jiménez MC. Methyl jasmonate-induced antioxidant defence in root apoplast from sunflower seedlings. Environ Exp Bot 2009;66:9-17.

9. Kuroda K, Inoue N, Ito Y, Kubota K, Sugimoto A, Kakuda T, et al. Sedative effects of the jasmine tea odor and (R)-(-)-linalool, one of its major odor components, on autonomic nerve activity and mood states. Eur J Appl Physiol 2005;95:107-114.

10. Fingrut O, Flescher E. Plant stress hormones suppress the proliferation and induce apoptosis in human cancer cells. Leukemia 2002;16:608-616.

11. Fingrut O, Reischer D, Rotem R, Goldin N, Altboum I, Zan-Bar I, et al. Jasmonates induce nonapoptotic death in high-resistance mutant p53-expressing B-lymphoma cells. BrJ Pharmacol 2005; 146:800-808.

12. Flescher E. Jasmonates--a new family of anti-cancer agents. Anticancer Drugs 2005;16:911-916.

13. Ofer K, Gold D, Flescher E. Methyl jasmonate induces cell cycle block and cell death in the amitochondriate parasite Trichomonas vaginalis. Int J Parasitol 2008;38:959-968.

14. Palmieri B, lannitti T, Capone S, Flescher E. A preliminary study of the local treatment of preneoplastic and malignant skin lesions using methyl jasmonate. Eur Rev Med Pharmacol Sci 2011;15:333-336.

15. Raviv Z, Zilberberg A, Cohen S, Reischer-Pelech D, Horrix $\mathrm{C}$, Berger MR, et al. Methyl jasmonate down-regulates survivin expression and sensitizes colon carcinoma cells towards TRAIL-induced cytotoxicity. Br J Pharmacol 2011;164: 1433-1444.

16. Hossain $\mathrm{SJ}$, Aoshima $\mathrm{H}$, Koda $\mathrm{H}$, Kiso Y. Fragrances in oolong tea that enhance the response of GABAA receptors. Biosci Biotechnol Biochem 2004;68:1842-1848.

17. Annafi OS, Aluko OM, Eduviere AT, Omorogbe O, Umukoro S. Probable mechanisms involved in the antipsychotic-like activity of methyl jasmonate in mice. Naunyn Schmiedebergs Arch Pharmacol 2017;390:883-892.

18. Adebesin A, Adeoluwa OA, Eduviere AT, Umukoro S. Methyl jasmonate attenuated lipopolysaccharide-induced depressive-like behaviour in mice. J Psychiatr Res 2017;94: 29-35.

19. Eduviere AT, Omorogbe O, Umukoro S. Methyl jasmonate ameliorates memory deficits in mice exposed to passive avoidance paradigm. J Neurosci Res 2017;1:6.

20. Eduviere AT, Umukoro S, Aderibigbe AO, Ajayi AM, Adewole FA. Methyl jasmonate enhances memory performance through inhibition of oxidative stress and acetylcholinesterase activity in mice. Life Sci 2015;132:20-26.

21. Solomon U, Eduviere AT. Methyl jasmonate attenuates memory dysfunction and decreases brain levels of biomarkers of neuroinflammation induced by lipopolysaccharide in mice. Brain Res Bull 2017;131:133-141.

22. Umukoro S, Aluko OM, Eduviere AT, Owoeye O. Evaluation of adaptogenic-like property of methyl jasmonate in mice exposed to unpredictable chronic mild stress. Brain Res Bull 2016;121:105-114.

23. Aluko OM, Umukoro S, Annafi OS, Adewole FA, Omorogbe O. Effects of methyl jasmonate on acute stress responses in mice subjected to forced swim and anoxic tests. Sci Pharm 2015;83:635-644.

24. Ghasemi Pirbalouti A, Sajjadi SE, Parang K. A review (research and patents) on jasmonic acid and its derivatives. Arch Pharm (Weinheim) 2014;347:229-239.

25. Scognamiglio J, Jones L, Letizia CS, Api AM. Fragrance material review on methyl dihydrojasmonate. Food Chem Toxicol 2012;50 Supp/ 3:S562-S571.

26. Environmental Protection Agency (EPA). Methyl jasmonateexemption from the requirement of a tolerance. Washington, D.C:Environmental Protection Agency;2013. p.22789-22794.

27. Food and Agriculture Organization of the United Nations (FAO); World Health Organization (WHO). Joint FAO/WHO Expert Committee on Food Additives (JECFA). Geneva:World Health Organization;2004.

28. Hoehn-Saric R. Neurotransmitters in anxiety. Arch Gen Psychiatry 1982;39:735-742.

29. Kaur S, Singh R. Role of different neurotransmitters in anxiety: a systemic review. Int J Pharm Sci Res 2017;8:411-421.

30. Martin El, Ressler KJ, Binder E, Nemeroff CB. The neurobiology of anxiety disorders: brain imaging, genetics, and psychoneuroendocrinology. Psychiatr Clin North Am 2009; 32:549-575.

31. Nuss P. Anxiety disorders and GABA neurotransmission: a disturbance of modulation. Neuropsychiatr Dis Treat 2015; 11:165-175.

32. Annafi OS, Umukoro S, Eduviere AT. Evaluation of the anticonvulsant and anxiolytic potentials of methyl jasmonate in mice. Sci Pharm 2014;82:643-654.

33. Cowen PJ. Neuroendocrine and neurochemical processes in depression. Psychopathol Rev 2016;3:3-15.

34. Moret C, Briley M. The importance of norepinephrine in depression. Neuropsychiatr Dis Treat 2011;7(Supp/ 1):9-13.

35. Baars MY, Müller MJ, Gallhofer B, Netter P. Depressive and 
aggressive responses to frustration: development of a questionnaire and its validation in a sample of male alcoholics. Depress Res Treat 2011;2011:352048.

36. Palazidou E. The neurobiology of depression. Br Med Bull 2012;101:127-145.

37. Umukoro S, Akinyinka AO, Aladeokin AC. Antidepressant activity of methyl jasmonate, a plant stress hormone in mice. Pharmacol Biochem Behav 2011;98:8-11.

38. Allison DJ, Ditor DS. The common inflammatory etiology of depression and cognitive impairment: a therapeutic target. J Neuroinflammation 2014;11:151.

39. Zomkowski AD, Santos AR, Rodrigues AL. Putrescine produces antidepressant-like effects in the forced swimming test and in the tail suspension test in mice. Prog Neuropsychopharmacol Biol Psychiatry 2006;30:1419-1425.

40. Blair RJ. Psychopathy, frustration, and reactive aggression: the role of ventromedial prefrontal cortex. Br J Psychol 2010; 101(Pt 3):383-399.

41. Tam FW-m, Taki M. Bullying among girls in Japan and Hong Kong: an examination of the frustration-aggression model. Educ Res Eval 2007;13:373-399.

42. Umukoro S, Eduviere AT, Aladeokin AC. Anti-aggressive activity of methyl jasmonate and the probable mechanism of its action in mice. Pharmacol Biochem Behav 2012;101: 271-277.

43. de Boer SF, Koolhaas JM. 5-HT1A and 5-HT1B receptor agonists and aggression: a pharmacological challenge of the serotonin deficiency hypothesis. Eur I Pharmacol 2005;526: 125-139.

44. Gowin JL, Swann AC, Moeller FG, Lane SD. Zolmitriptan and human aggression: interaction with alcohol. Psychopharmacology (Berl) 2010;210:521-531.

45. Nelson RJ, Chiavegatto S. Aggression in knockout mice. ILAR J 2000;41:153-162.

46. Takahashi A, Miczek KA. Neurogenetics of aggressive behavior: studies in rodents. Curr Top Behav Neurosci 2013; 17:3-44.

47. McEwen BS. Central effects of stress hormones in health and disease: understanding the protective and damaging effects of stress and stress mediators. Eur J Pharmacol 2008;583: 174-185.

48. Rajkumar R, Wu Y, Farooq U, Tan WH, Dawe GS. Stress activates the nucleus incertus and modulates plasticity in the hippocampo-medial prefrontal cortical pathway. Brain Res Bull 2016;120:83-89.

49. McEwen BS, Nasca C, Gray JD. Stress effects on neuronal structure: hippocampus, amygdala, and prefrontal cortex. Neuropsychopharmacology 2016;41:3-23.

50. Oken BS, Chamine I, Wakeland W. A systems approach to stress, stressors and resilience in humans. Behav Brain Res 2015;282:144-154.

51. Panossian AG. Adaptogens in mental and behavioral disorders. Psychiatr Clin North Am 2013;36:49-64.
52. Rothman SM, Mattson MP. Adverse stress, hippocampal networks, and Alzheimer's disease. Neuromolecular Med 2010:12:56-70.

53. Fendt M, Fanselow MS. The neuroanatomical and neurochemical basis of conditioned fear. Neurosci Biobehav Rev 1999;23:743-760.

54. Gold PE. The use of avoidance training in studies of modulation of memory storage. Behav Neural Biol 1986;46: 87-98.

55. Baarendse PJ, van Grootheest G, Jansen RF, Pieneman AW, Ogren SO, Verhage M, et al. Differential involvement of the dorsal hippocampus in passive avoidance in C57bl/6J and DBA/2J mice. Hippocampus 2008;18:11-19.

56. McGaugh JL. The amygdala modulates the consolidation of memories of emotionally arousing experiences. Annu Rev Neurosci 2004;27:1-28.

57. Aluko OM, Umukoro S. Methyl jasmonate reverses chronic stress-induced memory dysfunctions through modulation of monoaminergic neurotransmission, antioxidant defense system, and Nrf2 expressions. Naunyn Schmiedebergs Arch Pharmacol 2020;393:2339-2353.

58. Kreyenbuhl J, Buchanan RW, Dickerson FB, Dixon LB. The Schizophrenia Patient Outcomes Research Team (PORT): updated treatment recommendations 2009. Schizophr Bull 2010;36:94-103.

59. Ray WA, Chung CP, Murray KT, Hall K, Stein CM. Atypical antipsychotic drugs and the risk of sudden cardiac death. $\mathrm{N}$ Eng/ J Med 2009;360:225-235.

60. Draper ML, Stutes DS, Maples NJ, Velligan DI. Cognitive adaptation training for outpatients with schizophrenia. J Clin Psychol 2009;65:842-853.

61. Barch DM, Sheffield JM. Cognitive impairments in psychotic disorders: common mechanisms and measurement. World Psychiatry 2014;13:224-232.

62. Annafi O. Evaluation of antipsychotic effects of methyl jasmonate in mice. Ibadan:University of Ibadan;2017. [Dissertation].

63. Lakshmi B, Sudhakar M. Screening of Psidium guajava leaf extracts for antistress activity in different experimental animal models. Pharmacogn Res 2009;1:359-366.

64. Larzelere MM, Jones GN. Stress and health. Prim Care 2008:35:839-856.

65. Panossian A, Wikman G. Effects of adaptogens on the central nervous system and the molecular mechanisms associated with their stress-protective activity. Pharmaceuticals (Basel) 2010;3:188-224.

66. Vaváková M, Duuračková Z, Trebatická J. Markers of oxidative stress and neuroprogression in depression disorder. Oxid Med Cell Longev 2015;2015:898393.

67. Munhoz CD, García-Bueno B, Madrigal JL, Lepsch LB, Scavone C, Leza JC. Stress-induced neuroinflammation: mechanisms and new pharmacological targets. Braz J Med Biol Res 2008;41:1037-1046.

68. Aluko OM, Umukoro S. Role of purinergic signaling path- 
ways in the adaptogenic-like activity of methyl jasmonate in rats exposed to unpredictable chronic mild stress. Drug Metab Pers Ther 2020. doi: 10.1515/dmdi-2020-0117. [Epub ahead of print]

69. Zhu Q, Gu L, Wang Y, Jia L, Zhao Z, Peng S, et al. The role of alpha-1 and alpha-2 adrenoceptors in restraint stress-induced liver injury in mice. PLoS One 2014;9:e92125.

70. Han SG, Kim Y, Kashon ML, Pack DL, Castranova V, Vallyathan V. Correlates of oxidative stress and free-radical activity in serum from asymptomatic shipyard welders. Am J Respir Crit Care Med 2005;172:1541-1548.

71. Adelaja AO, Oluwole OG, Aluko OM, Umukoro S. Methyl jasmonate delays the latency to anoxic convulsions by normalizing the brain levels of oxidative stress biomarkers and serum corticosterone contents in mice with repeated anoxic stress. Drug Metab Pers Ther 2020. doi: 10.1515/dmpt2020-0129. [Epub ahead of print]

72. Shanmugarajan T. Potential of plant stress hormone methyl jasmonate against lipopolysaccharide attenuated oxidative stress and arthritis in experimental animals. Int I Green Pharm 2018;12 Suppl 3:S561-S569.

73. Gadamsetty G, Maru S, Sarada N. Antioxidant and anti-inflammatory activities of the methanolic leaf extract of traditionally used medicinal plant Mimusops elengi L. J Pharm Sci Res 2013;5:125-130.

74. Oyedapo O, Adewunmi C, Iwalewa E, Makanju V. Analgesic, antioxidant and anti-inflammatory related activities of 2'hydroxy-2,4'-dimethoxychalcone and 4-hydroxychalcone in mice. J Biol Sci 2008;8:131-136.

75. Dinarello CA. Anti-inflammatory agents: present and future. Cell 2010;140:935-950.

76. Ming Z, Wotton CA, Appleton RT, Ching JC, Loewen ME, Sawicki G, et al. Systemic lipopolysaccharide-mediated alteration of cortical neuromodulation involves increases in monoamine oxidase-a and acetylcholinesterase activity. J Neuroinflammation 2015;12:37.

77. Frühauf PK, Ineu RP, Tomazi L, Duarte T, Mello CF, Rubin MA. Spermine reverses lipopolysaccharide-induced memory deficit in mice. J Neuroinflammation 2015;12:3.

78. Shaftel SS, Kyrkanides S, Olschowka JA, Miller JN, Johnson RE, O'Banion MK. Sustained hippocampal IL-1 beta overexpression mediates chronic neuroinflammation and ameliorates Alzheimer plaque pathology. J Clin Invest 2007;117: 1595-1604.

79. Song JH, Lee JW, Shim B, Lee CY, Choi S, Kang C, et al. Glycyrrhizin alleviates neuroinflammation and memory deficit induced by systemic lipopolysaccharide treatment in mice. Molecules 2013;18:15788-15803.

80. Hein AM, O'Banion MK. Neuroinflammation and memory: the role of prostaglandins. Mol Neurobiol 2009;40:15-32.

81. Hein AM, Stutzman DL, Bland ST, Barrientos RM, Watkins LR, Rudy JW, et al. Prostaglandins are necessary and sufficient to induce contextual fear learning impairments after interleukin-1 beta injections into the dorsal hippocampus. Neuroscience 2007;150:754-763.

82. Lee HJ, Maeng K, Dang HT, Kang GJ, Ryou C, Jung JH, et al. Anti-inflammatory effect of methyl dehydrojasmonate (J2) is mediated by the NF-KB pathway. J Mol Med (Berl) 2011;89: 83-90.

83. Dang HT, Lee YM, Kang GJ, Yoo ES, Hong J, Lee SM, et al. In vitro stability and in vivo anti-inflammatory efficacy of synthetic jasmonates. Bioorg Med Chem 2012;20:4109-4116.

84. Moon JM, Thapliyal N, Hussain KK, Goyal RN, Shim YB. Conducting polymer-based electrochemical biosensors for neurotransmitters: a review. Biosens Bioelectron 2018;102: 540-552.

85. Hasler G. Pathophysiology of depression: do we have any solid evidence of interest to clinicians? World Psychiatry 2010;9:155-161.

86. Adell A, Castro E, Celada P, Bortolozzi A, Pazos A, Artigas F. Strategies for producing faster acting antidepressants. Drug Discov Today 2005; 10:578-585.

87. Blokland A. Acetylcholine: a neurotransmitter for learning and memory? Brain Res Brain Res Rev 1995;21:285-300.

88. Hasselmo ME. The role of acetylcholine in learning and memory. Curr Opin Neurobiol 2006;16:710-715.

89. Alabi AO, Ajayi AM, Ben-Azu B, Omorobge O, Umukoro S. Methyl jasmonate ameliorates rotenone-induced motor deficits in rats through its neuroprotective activity and increased expression of tyrosine hydroxylase immunopositive cells. Metab Brain Dis 2019;34:1723-1736.

90. Tabrez S, Jabir NR, Shakil S, Greig NH, Alam Q, Abuzenadah $\mathrm{AM}$, et al. A synopsis on the role of tyrosine hydroxylase in Parkinson's disease. CNS Neurol Disord Drug Targets 2012; 11:395-409.

91. Johnson ME, Salvatore MF, Maiolo SA, Bobrovskaya L. Tyrosine hydroxylase as a sentinel for central and peripheral tissue responses in Parkinson's progression: evidence from clinical studies and neurotoxin models. Prog Neurobiol 2018;165-167:1-25.

92. Burnstock G. An introduction to the roles of purinergic signalling in neurodegeneration, neuroprotection and neuroregeneration. Neuropharmacology 2016;104:4-17.

93. Eduviere AT, Umukoro S, Adeoluwa OA, Omogbiya IA, Aluko OM. Possible mechanisms involved in attenuation of lipopolysaccharide-induced memory deficits by methyl jasmonate in mice. Neurochem Res 2016;41:3239-3249.

94. Brookmeyer R, Johnson E, Ziegler-Graham K, Arrighi HM. Forecasting the global burden of Alzheimer's disease. Alzheimers Dement 2007;3:186-191.

95. Smith MA, Rottkamp CA, Nunomura A, Raina AK, Perry G. Oxidative stress in Alzheimer's disease. Biochim Biophys Acta 2000;1502:139-144.

96. Luca M, Luca A, Calandra C. The role of oxidative damage in the pathogenesis and progression of Alzheimer's disease and vascular dementia. Oxid Med Cell Longev 2015;2015: 
504678.

97. Huang WJ, Zhang X, Chen WW. Role of oxidative stress in Alzheimer's disease. Biomed Rep 2016;4:519-522.

98. Weintraub MK, Bisson CM, Nouri JN, Vinson BT, Eimerbrink $\mathrm{MJ}$, Kranjac D, et al. Imatinib methanesulfonate reduces hippocampal amyloid- $\beta$ and restores cognitive function following repeated endotoxin exposure. Brain Behav Immun 2013;33:24-28.

99. Lee JW, Lee YK, Yuk DY, Choi DY, Ban SB, Oh KW, et al. Neuro-inflammation induced by lipopolysaccharide causes cognitive impairment through enhancement of beta-amyloid generation. J Neuroinflammation 2008;5:37.

100. Agostinho P, Cunha RA, Oliveira C. Neuroinflammation, oxidative stress and the pathogenesis of Alzheimer's disease. Curr Pharm Des 2010;16:2766-2778.

101. Sulzer D. Multiple hit hypotheses for dopamine neuron loss in Parkinson's disease. Trends Neurosci 2007;30:244-250.

102. Jenner P, Olanow CW. The pathogenesis of cell death in
Parkinson's disease. Neurology 2006;66(10 Suppl 4):S24S36.

103. Obeso JA, Rodriguez-Oroz MC, Goetz CG, Marin C, Kordower $\mathrm{JH}$, Rodriguez $\mathrm{M}$, et al. Missing pieces in the Parkinson's disease puzzle. Nat Med 2010;16:653-661.

104. Lang AE, Obeso JA. Challenges in Parkinson's disease: restoration of the nigrostriatal dopamine system is not enough. Lancet Neurol 2004;3:309-316.

105. O'Sullivan SS, Williams DR, Gallagher DA, Massey LA, Silveira-Moriyama L, Lees AJ. Nonmotor symptoms as presenting complaints in Parkinson's disease: a clinicopathological study. Mov Disord 2008;23:101-106.

106. Dhanalakshmi C, Janakiraman U, Manivasagam T, Justin Thenmozhi A, Essa MM, Kalandar A, et al. Vanillin attenuated behavioural impairments, neurochemical deficts, oxidative stress and apoptosis against rotenone induced rat model of Parkinson's disease. Neurochem Res 2016;41: 1899-1910. 